\title{
Online Gamified Learning Platforms (OGLPs) for Participatory Learning
}

\author{
Kenneth Shiu-Pong $\mathrm{Ng}^{1}$, Ivan Ka-Wai Lai ${ }^{1(凶)}$, and Kwan-Keung $\mathrm{Ng}^{2}$ \\ ${ }^{1}$ Faculty of International Tourism and Management, City University of Macau, Macao, China \\ \{kennethng, ivanlai\} acityu.mo \\ 2 International Hybrid Learning Society, Hong Kong, China \\ steven.ng@mail.com
}

\begin{abstract}
Nowadays, students, especially whose majors are practical subjects such as tourism and hospitality in tertiary education, are not interested in ways of learning knowledge through classroom learning. Online Gamified Learning Platforms (OGLPs) are helpful for tertiary education and adult learning, especially for courses involves practical skills. This research aims to identify factors that have significant impacts on tourism and hospitality students to choose OGLPs as their learning tool. This research is based on the Unified Theory of Acceptance and Use of Technology (UTAUT) model. According to the conditions of OGLPs, a new variable 'perceived playfulness' is added and also combined with other theory with variables 'knowledge improvement', 'engagement', and 'immersion'. 272 valid data were collected through questionnaires survey. Data analysis was performed by adopting SmartPLS. The results of the research implied that knowledge improvement, engagement, and immersion influence expectancy of performance and effort. The study has verified the applicability of UTAUT with concepts of fun and learning on studying the tools for gamified learning and participatory learning approaches. It also offers some recommendations for developers of OGLPs to optimize the design of OGLPs as well as a new model for studying the gamified learning and participatory learning approaches.
\end{abstract}

Keywords: UTAUT - Gamification · Online gamified platform · Perceived playfulness $\cdot$ Knowledge improvement $\cdot$ Engagement $\cdot$ Immersion

\section{Introduction}

The rapid development and growth of technologies have become popular issues and affect our daily lives. The use of technology benefits a lot of areas for example in education; and varies of mobile apps and computerized platforms are commonly available for educational purposes these days thanks to high-speed internet access. Thence, some educators are probing methods to motivate students using different kinds of mobile technologies with internet access for replenishing traditional classroom learning. Especially in some education fields with practical knowledge in tourism and hospitality education are valuable of bridging the divide between academic knowledge and practical skills as it includes practical knowledge among all education disciplines. However, it's been tough 
to stimulate students' interest as well as motivate them in tourism and hospitality education. Traditional learning approaches are supposed to lack motivation and effectiveness for learning. Though educators devote themselves to enhance the learning approaches, it's known that schools still have troubles increasing student's learning motivation and engagement [1]. Maier and Thomas [2] suggested that online learning platforms bring higher efficiency to most students comparing to traditional classroom design. Filippou, Cheong, and Cheong [3] also recommended gamified learning methods for establishing online learning platforms. They mentioned that gamified learning does better in balance learning and fun than games itself or as entertainment. This kind of online learning platforms is referred to as Online Gamified Learning Platforms (OGLPs), and it is a new concept for education which involves practical learning. To improve OGLPs for related education discipline, the games designed should include more business learning and practical knowledge in real-life. Therefore, it's necessary to identify the factors to implement implementing OGLPs education successfully. Since this study aims to find out the factors those conduce students to accept online gamified learning activities, this study applies UTAUT model which has four variables including performance expectancy, effort expectancy, social influence, and facilitating conditions. It is more suitable to test the acceptance of technology and examining the factors influencing students' behavioural intention (BI) toward using OGLPs. In this research, perceived playfulness will be added as another variable and it represents whether students enjoy the game-like learning activities. Other antecedent variables (knowledge improvement, engagement, and immersion) will also be tested. This study also provides solid recommendations for educators to deliver satisfied game-like learning experiences to students successfully. It offers a new model for understanding the gamified learning for practical knowledge.

\section{Literature Review}

\subsection{Gamification and Education}

Kapp, 2012 defined gamification is using game-based mechanics, aesthetics and game thinking to engage people, motivate action, promote learning, and solve problems. Gamification refers to service design aimed at providing game-like experiences to users, commonly with the end-goal of affecting user behaviour [4]. The game has become a common language to bring people together in different aspects with different kinds of game design [5]. A lot of game techniques and elements like points, insignias, leader boards, rewards, rankings, quests, challenges, and virtual loops, were developed by the concept and application of gamification. Dominguez et al. [6] mentioned the positive side of gamification is to facilitate in the process of the selected situation into a gamified experience, by combining the game factors, and letting participation become more interesting and more playfulness. Gamification has become more and more important in business and marketing areas, and has attracted the attention of academics, educators, and practitioners recently from many different areas and also extended into the area of in learning [7].

Gamification education is not a new concept; however, it has been more prominent when combining with technology. Seaborn and Fels suggested that education, the term 
"gamification" refers to digital game-based learning (DGBL) and serious games in general [7]. In addition, "Gamification" refers to use games as a channel to engage and motivate people to learn and practice how to solve problems in the real world [8]. Maier and Thomas suggested that online learning platforms involved more efficient to learn in practical knowledge for most students over traditional classroom settings [2]. Recently more and more learning platforms, especially online platforms, used gamification as one of the methods to motivate participants' interest and also learn practical skills more easily, even participants with different backgrounds. For example, students are able to utilise the platform of the vocational and professional education and training in Hong Kong (VPET City) to execute flexible learning as well as competency-based and taskoriented instructional strategies [9]. It motivates students to learn practical skills through online gamified methods, for example, Front office operations. In this research, a similar platform is proposed with more gamified elements to raise the participants' interest and learn practical skills in kitchen production. Also, another example is a brand new language learning mobile app DROP launched in 2018. It is a game-based language learning app and became one of the most popular language-learning apps by having more than 10 million downloads all over the world because of their game-based, interesting, and motivated learning approach [10]. Figure 1 shows an example of OGLPs.
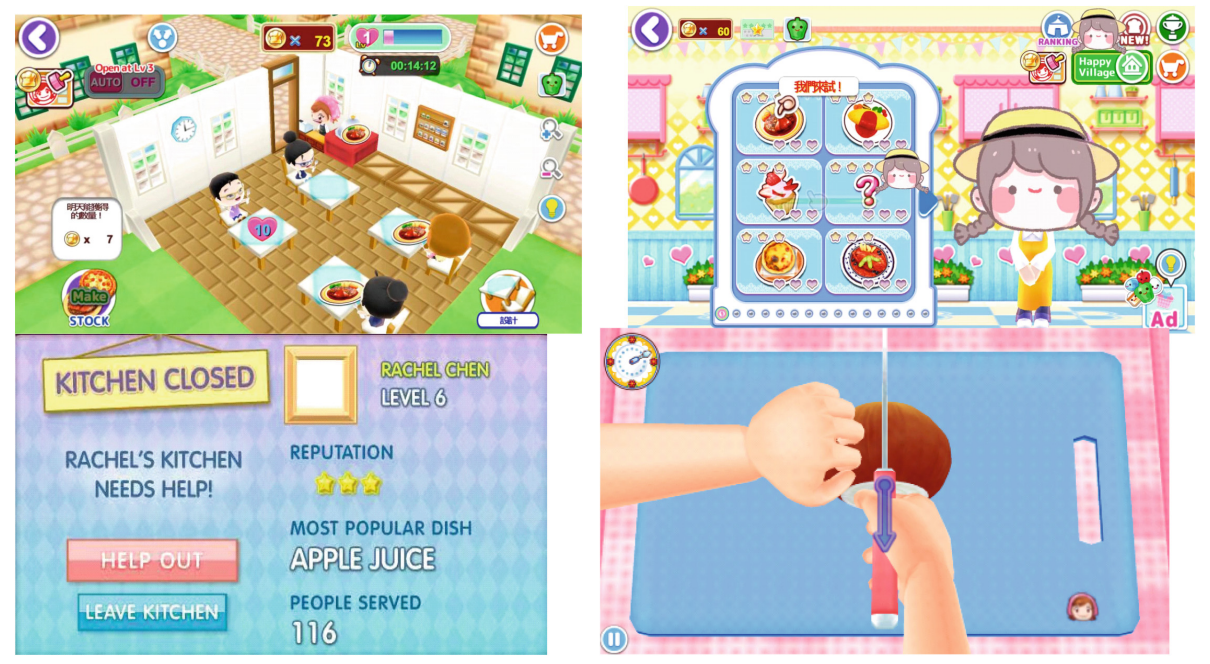

Fig. 1. An example of OGLPs

\subsection{The Unified Theory of Acceptance and Use of Technology (UTAUT)}

UTAUT was introduced to explain how people adapt to new technology and their further behaviours [11]. In the original UTAUT model, four key factors, including Performance Expectancy (PE), Effort Expectancy (EE), Social Influence (SI), and Facilitating Conditions (FC) were identified and widely used in recent studies. PE refers to the expectancy 
of people who uses the new system can increase their performance; EE refers to the expectancy of people how much efforts they need to put to use the new system; SI refers to how importance which people use the new technology or not in the social community; FC refers to how well technology organizations and infrastructure support their users when they use the new technology [11]. Using UTAUT to test new technology has been used in online platform already. UTAUT model has been used to test the adoption of mobile tour guide [12] and also the to the acceptance of mobile banking [13]. However, when considering the situation of this research like the interaction and game elements of this new technology, this study proposed to add new factors to modify the original UTAUT model.

In recent studies, additional factors were added to enrich the understandings of UTAUT. For example, Webster \& Martocchio defined "Perceived Playful-ness" (PP) as an individual's tendency to interact spontaneously, inventively and imaginatively with computer [14]. In the previous research, researchers tested the relationship between perceived playfulness and usage behaviour on mobile apps [15]. Thus, this study adds PP to the UTAUT to understand whether it significantly impact the BI. In addition, the research in playfulness has been related as a result of fun and cognitive immersion [16]. The results of Filippou, Cheong, \& Cheong's study showed that there are relationships among knowledge, engagement, usefulness and immersion [3]. Immersion refers to the degree of which people involved in the game's study and the game's strategies; and engagement refers to the engagement people gains when they are playing the games with enjoyment and interact with the game mechanism [17]. Knowledge improvement refers to whether students perceive their knowledge has been improved or not by adapting the gasified tool [3]. This research tests the relationship between knowledge improvement, immersion, and engagement as antecedent variables with performance expectancy, effort expectancy, and perceived playfulness.

In recent years, a lot of efforts are put on optimising the learning methods by educators while most of them have difficulties in motivating and engaging their students in the schools [1]. User motivation, engagement and enjoyment in non-gaming, computermediated environments are enhanced by developing gamification according to previous work. The concept of gamification is valued in different areas in education though the term of it might vary. One of the contributions on the study is to use the UTAUT model which related to acceptance of technology and other elements such as knowledge improvement, immersion, engagement, and perceived playfulness to create a more systematic and up to date approach to test the relationship and behavioural intention of participants for gamification in the education field by using online platforms.

\section{Research Hypothesis}

This research developed a model to measure students' preference on adapting gamified methods to learn, plus identify factors which affect their perception of using those methods. At a high-level, two different concepts: fun and learning are combined in the model combines. The constructs of Perceived playfulness, Immersion, and Engagement are included in the area of fun while the construct Knowledge improvement is included 
in the area of learning. The followings explore these constructs further and their connections among each other, which consists of the construction of the conceptual model eventually.

As mentioned previously, this study aims to use the UTAUT model to explain user behavioural intentions towards adopting new technology. As one of the key factors on university students' Behavioural intention (BI) to apply OGLPTs for studying practical knowledge, Perceived playfulness conduce significant impact like the other four constructs (PE, EE, SI, and FC). Knowledge Improvement, Engagement, and Immersion are proposed to be the antecedent factors which affect the students' attitude towards PE, $\mathrm{EE}$, and PP while EE is suggested to be the antecedent factor of PE and PP. Figure 2 shows the research model. Sixteen research hypotheses are listed below:

H1 Performance expectancy of online gamified learning platforms has a positive effect on Behavioural intention.

H2 Effort expectancy of online gamified learning platforms has a positive effect on Behavioural intention.

H3 Social influence of online gamified learning platforms has a positive effect on Behavioural intention.

H4 Facilitating conditions of online gamified learning platforms have a positive effect on Behavioural intention.

H5 Perceived playfulness of online gamified learning platforms has a positive effect on Behavioural intention.

H6-1 Knowledge improvement of online gamified learning platforms has a positive effect on Performance expectancy.

H6-2 Knowledge improvement of online gamified learning platforms has a positive effect on Effort expectancy.

H6-3 Knowledge improvement of online gamified learning platforms has a positive effect on perceived playfulness.

H7-1 Engagement of online gamified learning platforms has a positive effect on Performance expectancy.

H7-2 Engagement of online gamified learning platforms education has a positive effect on Effort expectancy.

H7-3 Engagement of online gamified learning platforms has a positive effect on perceived playfulness.

H8-1 Immersion of online gamified learning platforms has a positive effect on Performance expectancy.

H8-2 Immersion of online gamified learning platforms has a positive effect on Effort expectancy.

H8-3 Immersion of online gamified learning platforms has a positive effect on perceived playfulness.

H9-1 Effort expectancy of online gamified learning platforms has a positive effect on performance expectancy.

H9-2 Effort expectancy of online gamified learning platforms has a positive effect on perceived playfulness. 


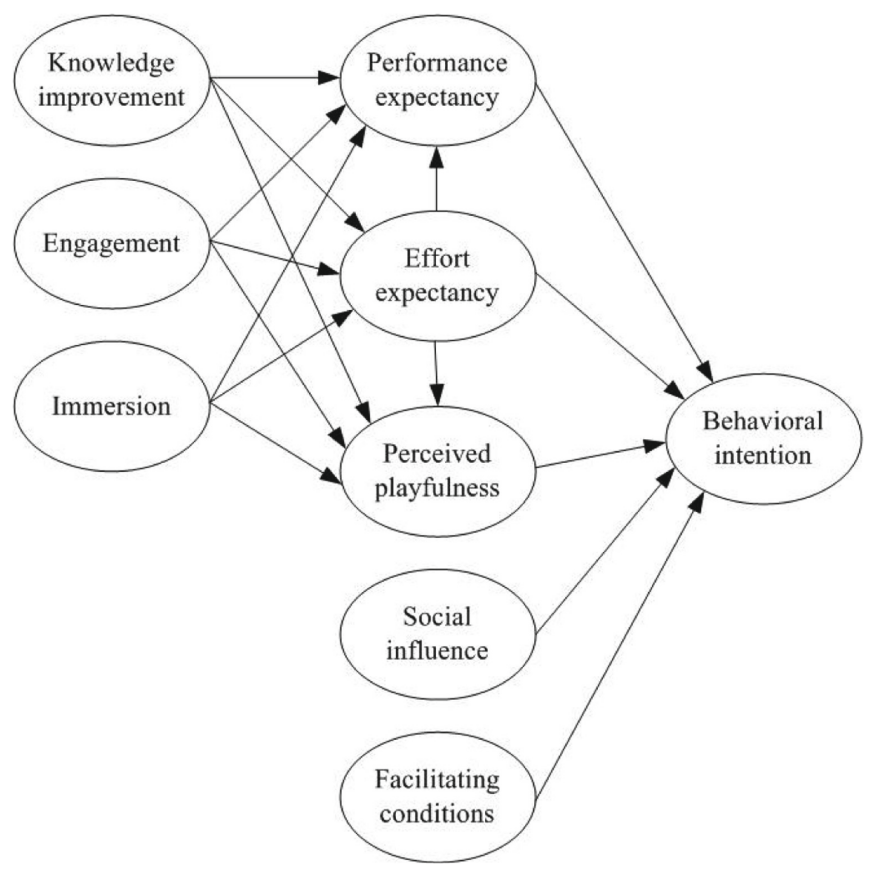

Fig. 2. Research model

\section{Methodology}

Quantitative methods are research techniques that are used to gather quantitative data or information dealing with numbers and anything that is measurable [18]. This study utilised the UTAUT model as the base theoretical model. This model was evaluated using a series of quantitative data analysis steps that best explain the predominant phenomena of the collected data. This study also aimed to test a set of hypotheses to understand and study the effects among the different constructs. Therefore, a quantitative approach was an appropriate method for this research.

\subsection{Survey Design}

This study used a questionnaire survey. The measurable items of the questionnaire borrowed from previous studies. The main survey and data analysis were a vital part of the whole study. The first part of the survey consists of 44 questions of the constructs. The second part of the survey consisted of 3 demographic questions to the respondents. The measurable items were the base of the survey and it consists of items from the UTAUT model with Perceived playfulness, Immersion, and Engagement and Knowledge added.

\subsection{Date Collection}

A pilot test was conducted with twenty questionnaires; the questionnaire has been revised based on the comments from respondents for official research. The researchers delivered 
the questionnaires to tourism students face to face in Macao University of Science and Technology and the City University of Macao, both Tourism related faculty. There were 300 questionnaires distributed via university students mentioned above in October 2019. 272 data were valid and analysed via SmartPLS software.

\section{Findings}

\subsection{Overview of Survey}

Among the 272 respondents, $60 \%$ of them are female students. Majority of the students are university's senior-year students (37\%). $34.5 \%$ of them are 20 years old, while $4 \%$ of them are 22 years old.

A 7-point Likert-type scale was applied for the questionnaires. The mean scores of $\mathrm{PE}, \mathrm{EE}, \mathrm{SC}, \mathrm{FC}, \mathrm{PP}, \mathrm{KN}, \mathrm{EG}, \mathrm{IM}$, and BI are ranged from 4.89 to 5.84. Comparing to other 8 contracts, IM got the lowest mean; the mean of IM-4 "I changed my feeling for the meaning of time while playing the game" is 4.89, and IM-3 "I temporarily forget worries about everyday life while playing the game" is 4.92 . Table 1 illustrates the mean and standard deviation scores of the nine constructs.

Table 1. Mean and Standard Deviation (S.D.) of measurable items

\begin{tabular}{l|l|l|l|l|l|l}
\hline & $P E 1$ & $P E 2$ & $P E 3$ & $E E 1$ & $E E 2$ & $E E 3$ \\
\hline MEAN & 5.518 & 5.445 & 5.426 & 5.787 & 5.842 & 5.809 \\
\hline S.D. & 1.011 & 1.063 & 1.023 & 1.108 & 1.082 & 1.138 \\
\hline & $S C 1$ & $S C 2$ & $S C 3$ & $F C 1$ & $F C 2$ & $F C 3$ \\
\hline MEAN & 5.290 & 5.199 & 5.044 & 5.162 & 5.243 & 5.566 \\
\hline S.D. & 1.095 & 1.136 & 1.169 & 1.139 & 1.157 & 1.217 \\
\hline & $P P 1$ & $P P 2$ & $P P 3$ & $K N 1$ & $K N 2$ & $K N 3$ \\
\hline MEAN & 5.684 & 5.691 & 5.669 & 5.566 & 5.327 & 5.551 \\
\hline S.D. & 1.186 & 1.118 & 1.135 & 1.083 & 1.188 & 1.063 \\
\hline & $K N 4$ & $K N 5$ & $E G 1$ & $E G 2$ & $E G 3$ & $E G 4$ \\
\hline MEAN & 5.452 & 5.574 & 5.57 & 5.46 & 5.419 & 5.235 \\
\hline S.D. & 1.149 & 1.096 & 1.226 & 1.153 & 1.173 & 1.244 \\
\hline & $E G 5$ & $E G 6$ & $I M 1$ & $I M 2$ & $I M 3$ & $I M 4$ \\
\hline MEAN & 5.349 & 5.096 & 5.136 & 4.926 & 4.915 & 4.893 \\
\hline S.D. & 1.286 & 1.283 & 1.216 & 1.270 & 1.139 & 1.234 \\
\hline & $I M 5$ & $I M 6$ & $B I 1$ & $B I 2$ & $B I 3$ & \\
\hline MEAN & 5.136 & 5.004 & 5.812 & 5.721 & 5.768 & \\
\hline S.D. & 1.194 & 1.220 & 1.017 & 1.062 & 1.122 & \\
\hline & & & & & &
\end{tabular}




\subsection{Reliability and Validity}

As shown in Table 2, reliability is tested by Cronbach Alpha and Composite Reliability, and the convergent validity is evaluated using Average Variance Extracted (AVE).

Table 2. Average Variance Extracted (AVE), Composite Reliability, and Cronbach's Alpha

\begin{tabular}{l|l|l|l}
\hline & AVE & $\begin{array}{l}\text { Composite } \\
\text { Reliability }\end{array}$ & Cronbach's Alpha \\
\hline PE & 0.724 & 0.887 & 0.809 \\
\hline EE & 0.767 & 0.908 & 0.849 \\
\hline SC & 0.779 & 0.872 & 0.695 \\
\hline FC & 0.634 & 0.838 & 0.711 \\
\hline PP & 0.807 & 0.926 & 0.880 \\
\hline KN & 0.587 & 0.876 & 0.824 \\
\hline EG & 0.551 & 0.880 & 0.838 \\
\hline IM & 0.568 & 0.887 & 0.847 \\
\hline BI & 0.832 & 0.937 & 0.899 \\
\hline
\end{tabular}

Furthermore, Table 3 shows the latent variable correlations; 7 out of 9 constructs are having correlation values lower than 0.85 which indicate reasonable and acceptable correlations among them.

Table 3. Latent variable correlations analysis

\begin{tabular}{l|l|l|l|l|l|l|l|l|l}
\hline & BI & EE & EG & FC & IM & KN & PE & PP & SC \\
\hline BI & 0.912 & & & & & & & & \\
\hline EE & 0.439 & 0.876 & & & & & & & \\
\hline EG & 0.554 & 0.483 & 0.743 & & & & & & \\
\hline FC & 0.539 & 0.388 & 0.499 & 0.796 & & & & & \\
\hline IM & 0.480 & 0.292 & 0.660 & 0.496 & 0.753 & & & & \\
\hline KN & 0.625 & 0.585 & 0.721 & 0.590 & 0.539 & 0.766 & & & \\
\hline PE & 0.561 & 0.499 & 0.479 & 0.587 & 0.456 & 0.583 & 0.851 & & \\
\hline PP & 0.626 & 0.505 & 0.697 & 0.555 & 0.584 & 0.687 & 0.494 & 0.898 & \\
\hline SC & 0.517 & 0.388 & 0.468 & 0.517 & 0.413 & 0.559 & 0.644 & 0.447 & 0.834 \\
\hline Remark & AVE & & & & & & & & \\
\hline
\end{tabular}

Remark: AVE - average variance extracted, Italic font - square-root of AVE 


\subsection{The Unified Theory of Acceptance and Use of Technology (UTAUT)}

To assess the significance of the path coefficients among these nine constructs, the researchers carried out a bootstrapping analysis in SmartPLS with 272 responses to 5000 samples. According to the SmartPLS results, the p-values of PE, SC, FC, PP and $\mathrm{KN}$ are less than 0.05. As a result, H1, H3, H4, H5, H6-1, H6-2, H6-3, are supported. For EG, only H7-2 and H7-3 are supported. While for IM, only H8-1 and H8-3 are supported. $\mathrm{H} 7-1$ from EG and H8-2 from IM are neglected because its p-value is over 0.05. For EE, $\mathrm{H} 9-1$ and $\mathrm{H} 9-2$ are supported but it is neglected on BI due to its p-value is over 0.05. The results of the Partial Least Squares Structural Equation Modeling (SmartPLS) is shown in Table 4 and Fig. 3.

Table 4. Results of SmartPLS analysis

\begin{tabular}{l|c|l|l}
\hline & Beta value & p-value & \\
\hline H1 Performance expectancy $\rightarrow$ Behavioural intention & 0.179 & 0.001 & Accepted \\
\hline H2 Effort expectancy $\rightarrow$ Behavioural intention & 0.053 & 0.314 & Rejected \\
\hline H3 Social influence $\rightarrow$ Behavioural intention & 0.146 & 0.005 & Accepted \\
\hline H4 Facilitating conditions $\rightarrow$ Behavioural intention & 0.131 & 0.020 & Accepted \\
\hline H5 Perceived playfulness $\rightarrow$ Behavioural intention & 0.373 & 0.000 & Accepted \\
\hline H6-1 Knowledge improvement $\rightarrow$ Performance expectancy & 0.343 & 0.000 & Accepted \\
\hline H6-2 Knowledge improvement $\rightarrow$ Effort expectancy & 0.507 & 0.000 & Accepted \\
\hline H6-3 Knowledge improvement $\rightarrow$ Perceived playfulness & 0.292 & 0.000 & Accepted \\
\hline H7-1 Engagement $\rightarrow$ Performance expectancy & -0.037 & 0.631 & Rejected \\
\hline H7-2 Engagement $\rightarrow$ Effort expectancy & 0.186 & 0.029 & Accepted \\
\hline H7-3 Engagement $\rightarrow$ Perceived playfulness & 0.292 & 0.000 & Accepted \\
\hline H8-1 Immersion $\rightarrow$ Performance expectancy & 0.222 & 0.000 & Accepted \\
\hline H8-2 Immersion $\rightarrow$ Effort expectancy & -0.104 & 0.153 & Rejected \\
\hline H8-3 Immersion $\rightarrow$ Perceived playfulness & 0.194 & 0.009 & Accepted \\
\hline H9-1 Effort expectancy $\rightarrow$ Performance expectancy & 0.252 & 0.000 & Accepted \\
\hline H9-2 Effort expectancy $\rightarrow$ Perceived playfulness & 0.137 & 0.014 & Accepted \\
\hline
\end{tabular}

To sum up, based on the reports and theories above, Perceived Expectancy (PE), Social Influence (SC), Facilitating Conditions (FC), and Perceived playfulness (PP) affect the Behavioural Intention (BI) toward using OGLPs of university students significantly as all hypotheses were supported. Knowledge improvement (KN) showed a most significant influence in PE, EE and PP while some of the hypotheses of Effort Expectancy (EE), Engagement (EG), and Immersion (IM) were not supported. 


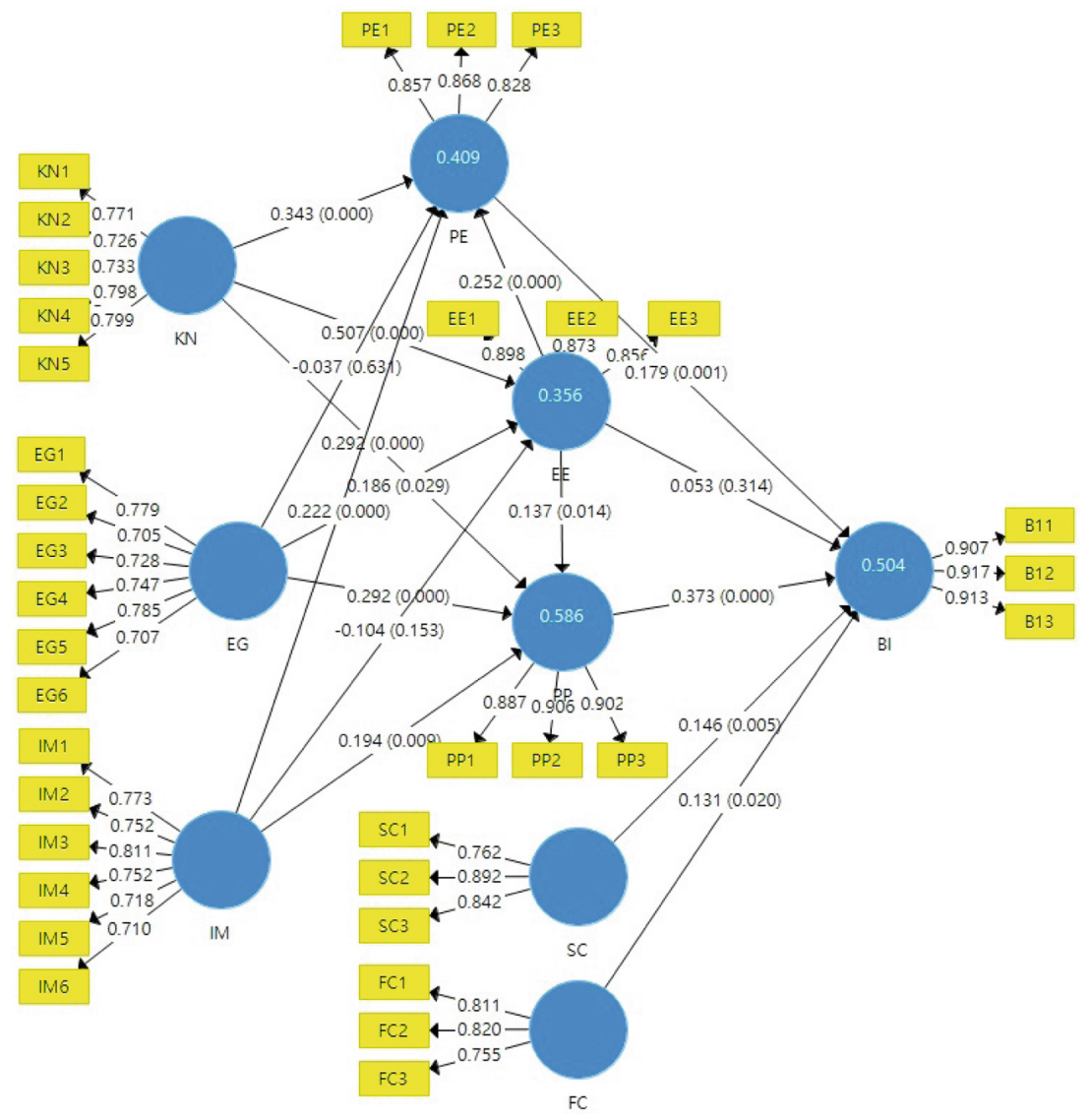

Fig. 3. Results of PLS-SEM analysis

\section{Discussion and Conclusion}

Nowadays, technology is becoming an important tool in education, particularly in higher education and vocational training that requires much more knowledge out of the textbooks. As visual reflection is a common language around the world, adopting mobiles apps is a way for people of all ages and nationalities to learn practical knowledge more efficiently, especially in industries which relate to service, such as hospitality service training, property management, and so on. It is not only the most popular way in daily communication but also a trend for people to pursue knowledge and skills more manageable and with higher motivation. In addition, online platforms have an advantage of not limited yourselves in a physical environment with nonstop learning when facing special occasion like 2019 Novel coronavirus SARI which affects daily life so much.

For the implications of this research, it uses the UTAUT model by SmartPLS software to analyse university students' BI toward applying OGLPs. It identifies factors which have significant impacts on the BI of university students toward adopting OGLPs; In 
addition, the results of the research may facilitate industries of service to find out crucial factors to improve staff's flexibility, efficiency, as well service quality by using mobile apps.

As mobile phone apps have been commonly used for many years already, EE is not essential when people choose apps or platforms like OGLPs according to the research results. Also, EG is not essential on PE because when people engaged in one issue, the performance will not be an important consideration as it has a bonding already to the apps.

Last but not least, Immersion is not essential for EE, because when people addicted to one app, the level of effort will not be treated as an important consideration as they will keep using it.

For the limitations of research, as the size of Macao is small, these results might be inappropriate to make generalised conclusions on other countries based on current research settings, and the education phenomenon was different from other areas in the world. Future studies were recommended to perform to test the research model in other regions and countries. In addition, this research added four new factors 'Immersion', 'Knowledge Improvement', 'Engagement' which act as antecedent factors and 'Perceived Playfulness' had positive influences on acceptance of technology towards adopting an ODTSA for the tourists to arrange their travel. Future studies might be considered adding other factors to investigate the relationship between the factors and the behaviour intention toward using ODTSA.

\section{References}

1. Lee, J., Hammer, J.: Gamification in education: what, how, why bother? Acad. Exch. Q. 15(2), $146(2011)$

2. Maier, T.A., Thomas, N.J.: Hospitality leadership course design and delivery: a blendedexperiential learning model. J. Hosp. Tourism Educ. 25(1), 11-21 (2013)

3. Filippou, J., Cheong, C., Cheong, F.: A model to investigate preference for use of gamification in a learning activity. Australas. J. Inf. Syst. 22 (2018)

4. Huotari, K., Hamari, J.: Defining gamification - a service marketing perspective. In: Proceedings of the 16th International Academic MindTrek Conference, Tampere, Finland, 3-5 October (2012)

5. Crawford, C.: The Art of Computer Game Design. Osborne-McGraw-Hill, Berkeley (1984)

6. Domínguez, A., Saenz-De-Navarrete, J., De-Marcos, L., Fernández-Sanz, L., Pagés, C., Martínez-Herráiz, J.: Gamifying learning experiences: practical implications and outcomes. Comput. Educ. 63, 380-392 (2013)

7. Seaborn, K., Fels, D.I.: Gamification in theory and action: a survey. Int. J. Hum Comput Stud. 74, 14-31 (2015)

8. Kapp, K.M.: The Gamification of Learning and Instruction: Game-Based Methods and Strategies for Training and Education. Pfeiffer, San Francisco (2012)

9. VPETCITY Programs: VPETCITY Programs (2018). https://sharepoint-auth.vtc.edu.hk/ adfs/ls/?wa=wsignin $1.0 \&$ wfresh $=0 \&$ wtrealm=urn:sharepoint:2016\&wctx $=$ https://sharep oint.vtc.edu.hk/vpetcity?returnUrl=https://sharepoint.vtc.edu.hk/vpetcity/Pages/QESS_T LPs.aspx

10. DROP Language: DROP Language Mobile Apps (2018). https://languagedrops.com/about/

11. Venkatesh, V., Morris, M.G., Davis, G.B., Davis, F.D.: User acceptance of information technology: toward a unified view. MIS Q. 27(3), 425-478 (2003) 
12. Lai, I.K.W.: Traveler acceptance of an app-based mobile tour guide. J. Hosp. Tourism Res. 39(3), 401-432 (2013)

13. Bhatiasevi, V.: An extended UTAUT model to explain the adoption of mobile banking. Inf. Dev. 32(4), 799-814 (2016)

14. Webster, J., Martocchio, J.J.: Microcomputer playfulness: development of a measure with workplace implications. MIS Q. 16(2), 201 (1992)

15. Hur, H.J., Lee, H.K., Choo, H.J.: Understanding usage intention in innovative mobile app service: comparison between millennial and mature consumers. Comput. Hum. Behav. 73, 353-361 (2017)

16. Ahn, T., Ryu, S., Han, I.: The impact of Web quality and playfulness on user acceptance of online retailing. Inf. Manag. 44(3), 263-275 (2007)

17. McMahan, A.: Immersion, engagement and presence: a method for analyzing 3-D video games. In: Wolf, M.J.P., Perron, B. (eds.) The Video Game Theory Reader, pp. 67-86. Routledge, London (2003)

18. Easterby-Smith, M., Thorpe, R., Lowe, A.: Management Research, 2nd edn. Sage Publications, Thousand Oaks (2002) 